\title{
Au-siRNA@ aptamer nanocages as a high-efficiency drug and gene delivery system for targeted lung cancer therapy
}

Yuming Yang 1,2, Yu Han ${ }^{1}$, Qiuyang Sun ${ }^{3}$, Jin Cheng ${ }^{1}$, Caixia Yue ${ }^{1,4}$, Yanlei Liu' ${ }^{1}$, Jie Song ${ }^{1,2}$, Weilin Jin ${ }^{1,2}$, Xianting Ding ${ }^{4}$, Jesús M. de la Fuente ${ }^{1,5}$, Jian Ni ${ }^{1}$, Xiaoqiang Wang ${ }^{3^{*}}$ and Daxiang Cui ${ }^{12^{*}}$ (D)

\begin{abstract}
Background: Gene and chemical therapy has become one of the rising stars in the field of molecular medicine during the last two decades. However, there are still numerous challenges in the development of efficient, targeted, and safe delivery systems that can avoid siRNA degradation and reduce the toxicity and adverse effects of chemotherapy medicine.
\end{abstract}

Results: In this paper, a highly efficient AS1411 aptamer modified, dsDNA and MMP-2 cleavable peptide-fabricated gold nanocage vehicle, which could load doxorubicin hydrochloride (DOX) and siRNAs to achieve a combination of tumor responsive genetic therapy, chemotherapy, and photothermal treatment is presented. Our results show that this combined treatment achieved targeted gene silencing and tumor inhibition. After nearly one month of treatment with DOX-loaded Au-siRNA-PAA-AS1411 nanoparticles with one dose every three days in mice, a synergistic effect promoting the eradication of long-lived tumors was observed along with an increased survival rate of mice. The combined genetic, chemotherapeutic, and photothermal treatment group exhibited more than 90\% tumor inhibition ratio (tumor signal) and a 67\% survival rate compared with a 30\% tumor inhibition ratio and a 0\% survival rate in the passive genetic treatment group.

Conclusions: The development of nanocarriers with double-stranded DNA and MMP-2 cleavable peptides provides a new strategy for the combined delivery of gene and chemotherapy medicine. Au-siRNA-PAA-AS1411 exerts high anticancer activities on lung cancer, indicating immense potentials for clinical application.

Keywords: Lung cancer, Gold nanoparticle, Gene delivery, Tumor targeted therapy, Gold nanocage

\footnotetext{
*Correspondence: Wangxiaoqiang419@163.com; dxcui@sjtu.edu.cn

2 National Center for Translational Medicine, Collaborative Innovational

Center for System Biology, Shanghai Jiao Tong University, 800 Dongchuan

RD, Shanghai 200240, People's Republic of China

3 Pediatric Neurological Disease Center, Xinhua Hospital, Shanghai

Jiaotong University School of Medicine, Number 1665, Kongjiang Road,

Shanghai 200092, People's Republic of China

Full list of author information is available at the end of the article
}

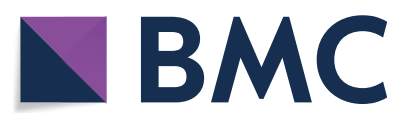

(c) The Author(s) 2021. This article is licensed under a Creative Commons Attribution 4.0 International License, which permits use, sharing, adaptation, distribution and reproduction in any medium or format, as long as you give appropriate credit to the original author(s) and the source, provide a link to the Creative Commons licence, and indicate if changes were made. The images or other third party material in this article are included in the article's Creative Commons licence, unless indicated otherwise in a credit line to the material. If material is not included in the article's Creative Commons licence and your intended use is not permitted by statutory regulation or exceeds the permitted use, you will need to obtain permission directly from the copyright holder. To view a copy of this licence, visit http://creativeco mmons.org/licenses/by/4.0/. The Creative Commons Public Domain Dedication waiver (http://creativecommons.org/publicdomain/ zero/1.0/) applies to the data made available in this article, unless otherwise stated in a credit line to the data. 


\section{Background}

Lung cancer is one of the most common malignant tumors in the world. The five-year survival rate of patients with lung cancer remains very low due to difficulties of early diagnosis, drug resistance, and relapse after treatment. So far, surgical treatment is considered to be the only radical curative method, but most patients have reached the advanced stage by the time they seek treatment, and thus the optimal window for radical surgery or radiotherapy is lost. New strategies are needed to improve the tolerability and efficacy of treatment for lung cancer. Gene therapy is an efficient and promising approach to treating malignant tumors by either degrading mRNAs or inhibiting their translation. Many siRNAs have been shown to be actively involved in metabolism, cell death, angiogenesis, metastasis and immunosuppression in cancer [1]. Using siRNAs as therapeutic agents for regulating cancer can alter the intrinsic properties of tumor cells and the tumor microenvironment. Increasing attention has been focused on gene therapy due to its potential use in treating a variety of diseases, including cancers, by delivering genetic drugs to the target tumor sites [2-4]. Among various genetic drugs, the vascular endothelial growth factor (VEGF) family (VEGF A, B, C, $\mathrm{D}$ and Placenta growth factor) has been the most widely investigated [4-9]. The development of VEGF-targeted genetic drugs, including VEGF-A receptors, small molecule tyrosine kinase inhibitors and antibodies, has been widely investigated, and these drugs have been confirmed to be efficient anti-angiogenesis therapies [10-12]. However, naked siRNAs are difficult to use for in vivo applications, as they are easily degraded by serum nucleases and are rapidly eliminated through renal excretion. Also, to efficiently deliver to target sites, siRNAs should be considered in sufficient numbers. Therefore, a suitable gene delivery system that can protect nucleic acids from degradation and selectively deliver a sufficient amount of siRNAs to target sites is needed.

Nanoparticles (NPs) are effective carriers of multiple therapeutic and diagnostic agents [13-17]. Various methods have been reported for the modification of nanoparticles to confer the NPs good bioavailability, low toxicity and a long circulation time [18-21]. NPs are now widely applied in oncology research for tumor imaging and theranostics [22-24]. NPs used for siRNA delivery have also been reported [25]. Chen et al. reported a magnetic mesoporous silica nanoparticle (M-MSN)-based siRNA delivery system for the delivery of VEGF-small interfering RNA (siRNA) [5]. Ding et al. reported polyethyleneimine (PEI)-modified single-walled carbon nanotubes to deliver VEGF-targeted siRNA (siVEGF) for the synergistic and targeted treatment of tumor angiogenesis [26]. James Finlay et al. synthesized polyethyleneimine-coated mesoporous silica nanoparticles (MSNs) for the delivery of siRNA, which led to a reduction in Twist1 [27]. However, these systems cannot protect the siRNA with a closed environment to avoid degradation. The amount of siRNAs delivered is also limited compared with the ratio of gene carries. In addition, a good vehicle should also have the ability to selectively transport oligonucleic acid-based therapeutics to the target sites and execute the controlled release the gene to the diseased tissue.

In the current study, a nanocage was designed for the co-delivery of gene and chemotherapy drugs. Au nanoparticles were selected as the vesicles due to their many promising characteristics, including controllable sizes and shapes, biocompatibility, nontoxicity, and ease of connecting with the target molecules due to the strong interactions with amine or thiol moieties. The distinguished X-ray attenuation property of Au nanoparticles enables these particles to serve as one of the most effective contrast agents for X-ray CT imaging. Besides, Au nanoparticles can absorb near-infrared laser frequencies to achieve thermal ablation of cancer cells [28-31]. Polyacrylic acid (PAA), a popularly used material, was used in this study to construct the surface of the cage by taking advantage of the numerous carboxylic acid groups available for biomolecule conjugation [32-35]. The strongly negative surface charge of PAA also conferred the Au nanocage good biocompatibility and water dispersity. Double-stranded DNA (dsDNA) molecules act as the rigid trestle in the gold nanocage structure. One single-stranded DNA molecule, ssDNA-2, was modified with thiol groups and anchored with the Au nanoparticle, and the complementary antisense strand, ssDNA-1, was modified with $\mathrm{NH}_{2}$ and connected with PAA through an amidation reaction. In addition, PAA was divided into two groups and modified with two kinds of complementary amino-modified oligonucleotides (ssDNA-3, ssDNA-4) and AS1411. ssDNA-2 was first anchored to the $\mathrm{Au}$ nanoparticle surface by the $\mathrm{Au}-\mathrm{S}$ bond, and then the PAAs were modified with the complementary antisense oligonucleotide, ssDNA-1, which was hybridized to ssDNA-2. The gold nanocages were closed through the complementary base pairing of DNA-3 and DNA-4 with DNA-5 (linked with the MMP-2 cleavable peptide). Then, a large number of dsDNA molecules and peptides were stacked on the surface of the Au nanocages, rendering the Au nanoparticles as closed nanocages. To further enhance the antitumor efficacy, doxorubicin was introduced into this nanocage system by taking advantage of the property that DOX can preferentially intercalate into double-stranded $5^{\prime}-\mathrm{GC}-3^{\prime}$ or $5^{\prime}-\mathrm{CG}-3^{\prime}$ to form a tightly coupled complex without chemical bond links [36]. The gold nanocages could selectively deliver the loading drugs and genes to the tumor sites due to modification 
of AS1411, anti-nucleolin aptamers for site-specific targeting against tumor cells, which overexpresses nucleolin receptors. The nanocages were destroyed by the matrix metalloproteinase (MMP)-2 enzymes, which were overexpressed around the tumor tissues by the cleavage of the enzyme-cleavable peptide chain (contained in DNA-5) on the surface of the gold nanocages. Following the cleavage of the peptide chain, the tumor-targeted and controlled drug release was achieved.

To our knowledge, this is the first proof of concept to construct a tumor responsive drug delivery nanocage system using Au nanoparticle, dsDNA, and MMP-2 cleavable peptide. The developed gold nanocage system shows good stability, excellent tumor inhibition ratio, and high gene delivery efficacy (Scheme 1).

\section{Results and discussion}

\section{Au nanocage design and characterization}

Citrate-coated gold nanoparticles of approximately $10 \mathrm{~nm}$ were selected as the core of the nanocage and were synthesized according to a previously reported method [37]. The specific anti-VEGF siRNA duplex with the sequence of 5'-CCCACAUACACACAUAUAUUU$3^{\prime}$ (sense) and $5^{\prime}$-UUGGGUGUAUGUGUGUAUAUA- ${ }^{\prime}$ (antisense) was selected for the subsequent gene therapy, which has been certified to be one of the most efficient siRNA sequences [38]. PAA 2000 was selected for the nanocage construction and was divided into two groups. The first group, PAA-1, was modified with ssDNA-3 (5'-AAAAGCGCGCGCGCGC-3'), ssDNA-1(AS1411 aptamer). The second group, PAA-2, was modified with ssDNA-1(AS1411 aptamer) and ssDNA-4 (5'-CGCGCG CGCGCGAAAA- $3^{\prime}$ ). AS1411 is an aptamer that targets nucleolin, which is abundant in the nucleus of normal cells but is also over expressed in the cell membrane of tumor cells, including prostate, lung, and breast cancers. The modification with AS1411 rendered the Au nanocage capable of delivering therapeutic genes to lung cancer cells. The Au nanoparticles were first modified with thiolated-DNA-2 and thiolated anti-VEGF siRNA through Au-S bonds (DNA-2 : siRNA $=1: 10$ molar ratio), then reacted with equal molar ratios of modified PAA-1 and PAA-2. The DNA braiding structure on the surface of sphere is shown in Fig. 1.

To avoid linking multiple gold nanoparticles on same PAA chain, a low concentration of ssDNA-2-modified gold nanoparticle was used. The dynamic light scattering (DLS) (Figure S2) and TEM images (Fig. 2) showed that the Au nanocage were stable and well dispersed. The average diameter of the Au core was approximately $\sim 10 \mathrm{~nm}$. The mean particle diameter of the Au nanocage was approximately $16 \mathrm{~nm}$ with an approximately $3-\mathrm{nm}$ shell thickness. The UV-Vis of the Au-siRNA and Au modified with ss-DNA exhibited a $5 \mathrm{~nm}$ and $3 \mathrm{~nm}$ wavelength shift, respectively, compared with the Au nanoparticles, showed that DNAs had successfully been modified on the surface of gold nanoparticles (Fig. 2d).

To evaluate the stability of the $\mathrm{Au}$ nanocages in serum, the in vitro release of siRNAs from the $\mathrm{Au}$ nanocages was investigated. In this experiment, siRNAs were modified with Cy5. The Au nanocages were incubated in cell culture medium containing $10 \%$ serum for up to $72 \mathrm{~h}$. During the first $8 \mathrm{~h}$, approximately $3 \%$ of the siRNAs were released. The cumulative release of the siRNA increased to $8 \%$ during the first $24 \mathrm{~h}$. The total release of siRNA reached $16 \%$ and $48 \%$ in the following 48 and $72 \mathrm{~h}$, respectively. Considering the antitumor efficiency of the Au nanocage, Doxorubicin hydrochloride (DOX) was also loaded into the gold nanocage in the last step of the Au nanocage construction according to the mechanism that DOX can preferentially intercalate into double-stranded -GC- base pairs to form a tightly coupled complex. The DOX release behavior was also investigated in cell culture medium containing $10 \%$ serum for up to $72 \mathrm{~h}$. In the first $8 \mathrm{~h}$, the cumulative release of DOX was controlled to within $1 \%$, and then the release increased to $5 \%$ at the 24 -h time point. The total amount of DOX release was within $7 \%$ for up to $72 \mathrm{~h}$ incubation, which effectively avoid the drug leakage on the way of distributing to the tumor sites (Fig. 3a). In order to study the release behavior of DOX from the gold nanocage at tumor microenvironment, the DOX release behavior at different $\mathrm{pH}$ solution were investigated and were shown in Additional file 1: Figure S3. The cumulative release of DOX was up to $28 \%$ at 24-h time point.

\section{In vitro targeting and anti-tumor effect of gold nanocages}

The lung cancer cell line NCI-H889, which was generated from disseminated cancer cells from a KPT mouse, were selected for the in vitro investigation of the cellular uptake and antitumor efficiency of the Au nanocages. The ultrastructural TEM images revealed that the Au-dsDNA-PAA-AS1411 nanoparticles were swallowed by the NCI-H889 cells and were mainly concentrated in the endosomes or lysosomes (Fig. 3c, d). Confocal images of Au nanocages with and without the AS1411 aptamer modification revealed that both Au-siRNA-PAA-AS1411 and Au-siRNA-PAA could enter the NCI-H889 lung cancer cells. The apparent uptake of Au-siRNA-PAA-AS1411 was observed after $1 \mathrm{~h}$ of incubation. The uptake of AusiRNA-PAA was less efficient than that of Au-siRNAPAA-AS1411 at same incubation time, as evidenced by the weaker fluorescence intensity (Fig. 4a, b). The VEGF silencing efficiency of both Au-siRNA-PAA-AS1411 and 


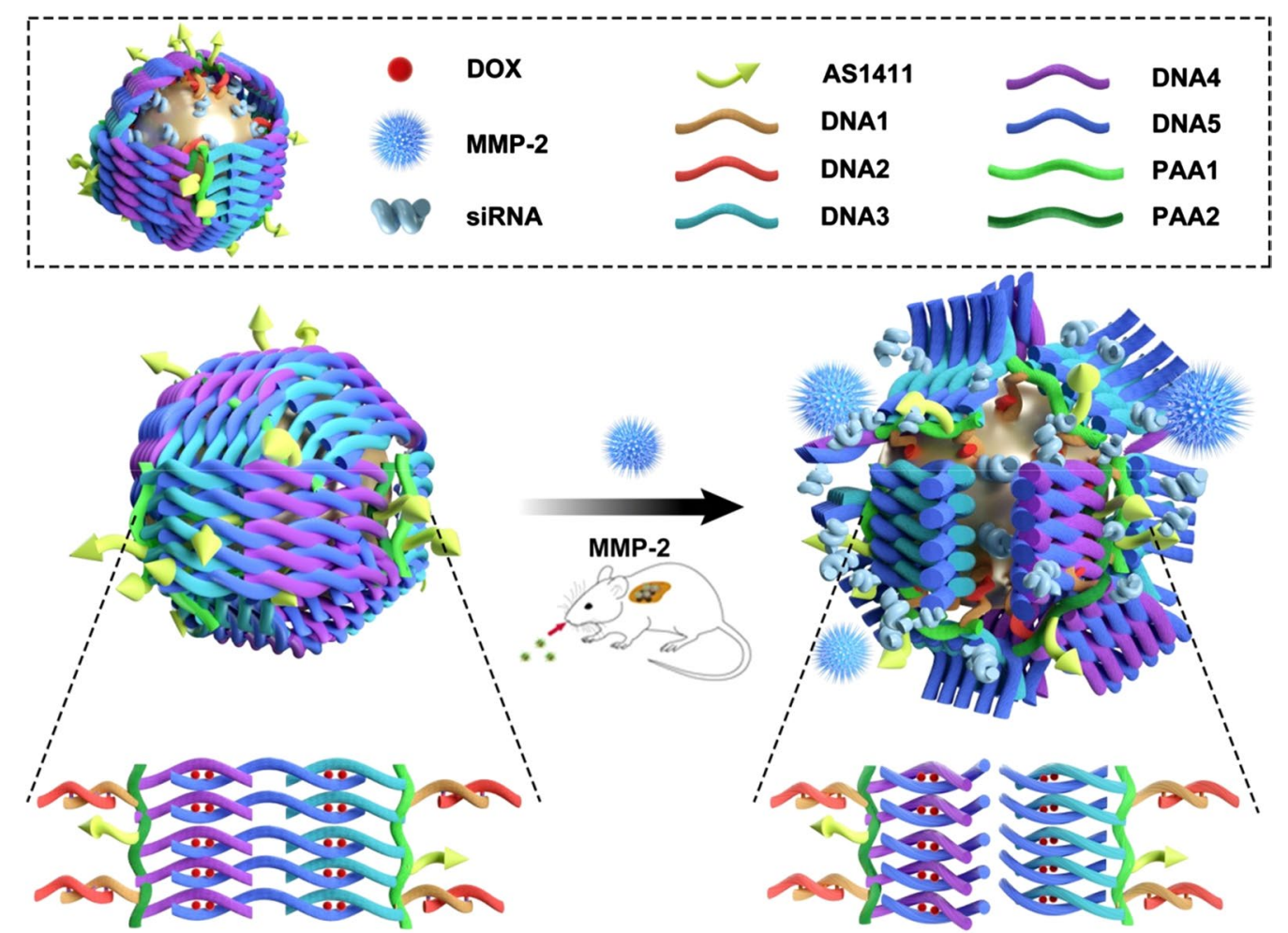

Scheme 1 The schematic illustration of the construction of gold nanocages and the tumor-induced gene- and DOX-releasing mechanism. Gold nanoparticles were first decorated with thiolated-DNA-2 and thiolated anti-VEGF siRNAs based on the thiol-Au bond. PAA-1 was modified with ssDNA-1, ssDNA-3, and the AS1411 aptamer. PAA-2 was modified with ssDNA-1, ssDNA-4, and the AS1411 aptamer; then, the ssDNA-2 and siRNA-conjugated (DNA-2: siRNA = 1:10 molar ratio) gold nanoparticles were conjugated with equal molar ratios of PAA-1, PAA-2, and DNA-5 to generate the rigid trestle of the gold nanocages. The gold nanocage were finally closed through the complementary base pairing of DNA-3 and DNA-4 with DNA-5

Au-siRNA-PAA was evaluated in NCI-H889 lung cancer cells. Both Au-siRNA-PAA-AS1411 and Au-siRNA-PAA exhibited an apparent gene silencing efficiency in a dosedependent manner. A gene silencing efficacy as high as $80 \%$ was observed for the Au-siRNA-PAA-AS1411 group at the mRNA level by qPCR at a dose of $10 \mathrm{nM}$ gold nanocages up to $48 \mathrm{~h}$ of incubation (Fig. 3b). The VEGF gene silencing efficiency tends to be stable when the concentration of Au-siRNA-PAA-AS1411 higher than $10 \mathrm{nM}$. The antitumor efficacy of the Au-siRNA-PAAAS1411 nanocages was also evaluated by flow cytometry analysis (Fig. 4c). Annexin V-FITC/Propidium Iodide double-staining was used to determine the apoptosis rate of NCI-H889 cells induced by siRNA or siRNA combined with the chemotherapy drug and laser irradiation. The cells were divided into five groups, namely, the control group, the siRNA group, the Au-siRNA-PAA group and the Au-siRNA-PAA-AS1411 group. For the siRNA group, the cells were incubated with siRNA and treated with gene therapy only; for the Au-siRNA-PAA group, the cells were incubated with DOX-loaded Au-siRNA-PAA nanocages and treated with the combination of gene and chemotherapy therapy; for the Au-siRNA-PAA-AS1411 group, the cells were incubated with DOX-loaded AusiRNA-PAA-AS1411 nanocages and target-treated with gene therapy, chemotherapy and laser irradiation; for the Au-siRNA-PAA-AS1411(no DOX) group, cells were incubated with Au-siRNA-PAA-AS1411 without DOX loading and targeted treated with the combination of siRNA and thermotherapy. The untreated cells served as the control group. Maximal apoptosis and necrosis were observed in the Au-siRNA-PAA-AS1411 group, with subpopulations exhibiting as much as $49.46 \%$ early apoptosis and $37.51 \%$ late apoptosis. The cell apoptosis level decreased to $68.97 \%$ for the Au-siRNA-PAA group; however, both of these groups exhibited much higher cell apoptosis levels compared to the siRNA group.

\section{In vivo targeting and anti-tumor effect of gold nanocages}

Next, Au-siRNA-PAA-AS1411 was investigated for its ability to deliver anti-VEGF siRNA to a lung cancer orthotopic murine model of BALB/c nude mice expressing NCI-H889 lung cancer cells. To avoid the nonspecific uptake of the antitumor drugs, a complex system 


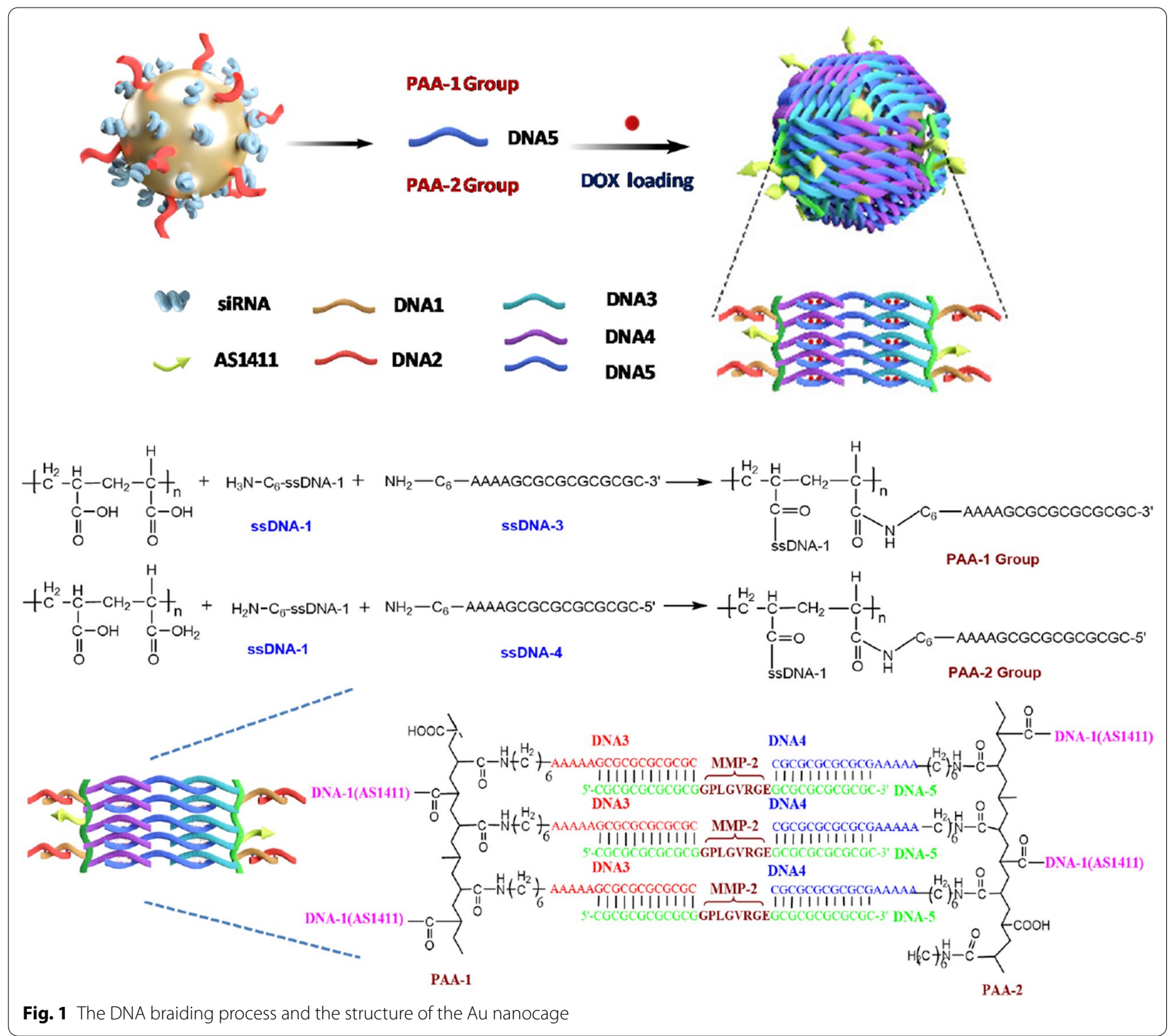

which allows for the inhalation-mediated local delivery of an anticancer drug was employed to administer the Au-siRNA-PAA/ Au-siRNA-PAA-AS1411 nanocages to the lung tumors. In vivo biodistribution imaging studies were applied for the investigation of the tumor-targeting ability of Au-siRNA-PAA-AS1411. BALB/c nude mice bearing NCI-H889 lung tumors were treated with $1 \mathrm{~mL}$ of $800 \mu \mathrm{g} \mathrm{mL}^{-1} \mathrm{Au}$-siRNA-PAA-AS1411 and AusiRNA-PAA through inhalation-mediated local delivery. In vivo imaging was performed over a time-course from 1 to $24 \mathrm{~h}$. As shown in Fig. 5, the Au-siRNA-PAA-AS1411 nanocages were randomly concentrated at the lung site at $1 \mathrm{~h}$ post-delivery. At the 4-hr time point, the fluorescence signal from the gold nanocages became decreased and more concentrated toward the tumor signal; thereafter, until $16 \mathrm{hrs}$, the gold nanocage signal exhibited a great degree of overlay with tumor signal. The signal lasted up to $24 \mathrm{~h}$ at the lung tumor site. The quantitative biodistribution of Au-siRNA-PAA-AS1411 gold nanocages was also investigated by isolated organ imaging and ROI (region of interest) analysis of the mean organ fluorescence intensity (Fig. 5b, d, e). The results showed that the Au-siRNA-PAA-AS1411 gold nanocages could target the lung tumor, and moreover, they exhibited a long retention time. The fluorescence intensity of the Au-siRNAPAA-AS1411 gold nanocages on the lung (tumor) was much stronger compared with other organs. A lower mean fluorescence intensity was also observed for the Au-siRNA-PAA group (Fig. 5b). The fluorescence signal from the Au-siRNA-PAA-AS1411 gold nanocages at the 

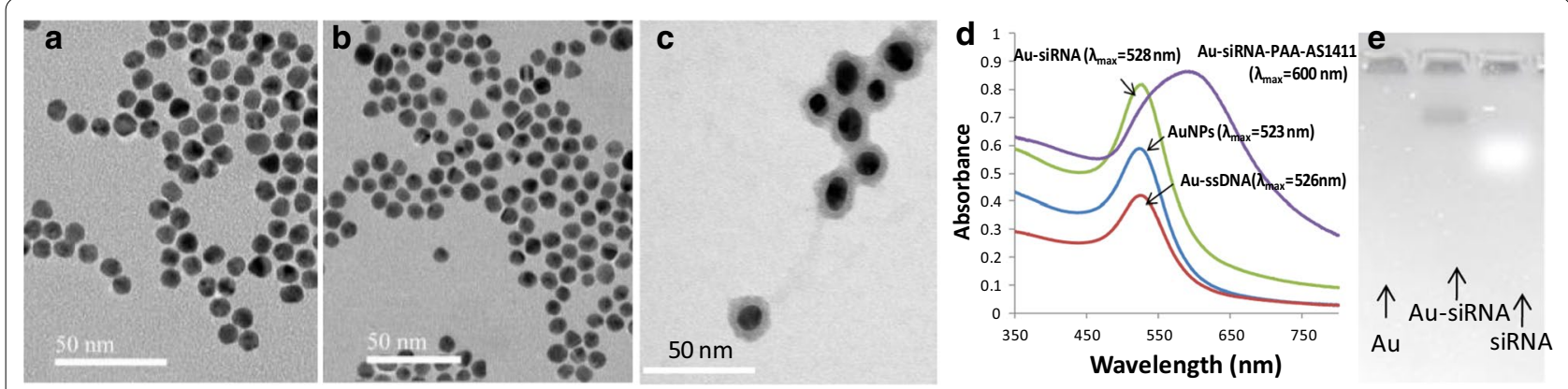

Fig. 2 TEM images and UV-vis absorption spectrum of gold nanoparticles. a TEM images of 10-nm citrate-coated gold nanoparticles; $\mathbf{b}$ Low magnification TEM images of Au-siRNA-PAA-AS1411 nanocages; c TEM images of Au-siRNA-PAA-AS1411 nanocages with negative staining; $\mathbf{d}$ Changes in the UV-Vis absorption spectrum of citrate-coated gold nanoparticles, Au-ssDNA and Au-dsDNA; The UV-Vis of the Au-dsDNA and Au-ssDNA (DNA-2: siRNA = 1:10 molar ratio) exhibited a $5 \mathrm{~nm}$ and $3 \mathrm{~nm}$ wavelength shift, respectively, compared with the Au nanoparticles, showing the successful modification of DNAs on the surface of gold nanoparticles. $\mathbf{e}$ The gel image of Au, Au-siRNA, and siRNA showing the successful coating of siRNAs. The band of siRNA located at a molecular weight lower than that of Au-siRNA indicates that siRNAs were successfully conjugated on the surface of Au nanoparticles
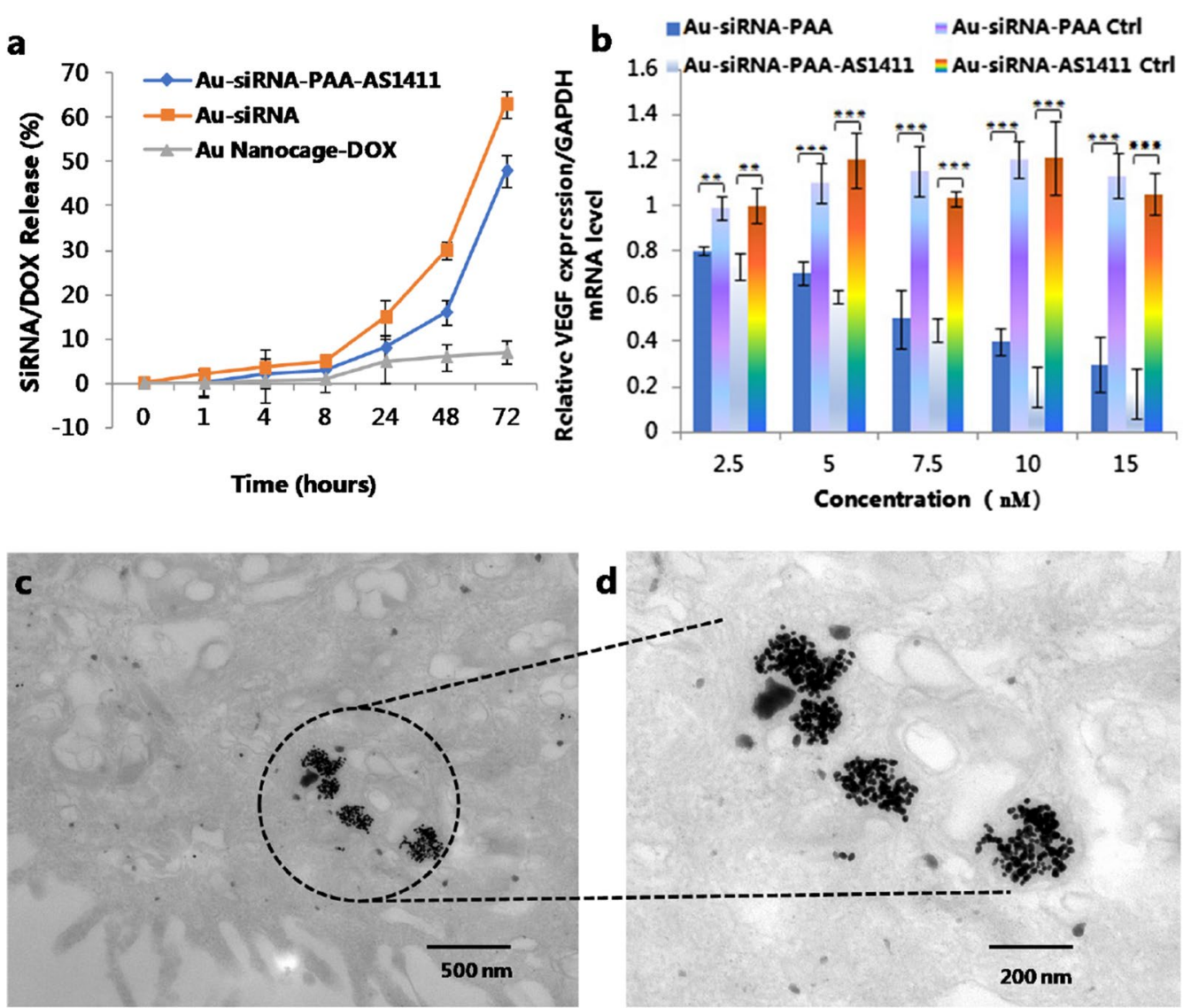

Fig. 3 In vitro siRNA / drug release, gene silence efficacy and ultrastructural TEM images of lung tumor tissue from treated mice. a siRNA release from the Au-siRNA-PAA-AS1411 nanocages and Au-siRNA; DOX release from Au-siRNA-PAA-AS1411 nanocages; $\mathbf{b}$ The silencing effect of Au-siRNA-PAA-AS1411 and Au-siRNA-PAA in the lung-adenocarcinoma NCI-H889 cell line. The gene silencing efficacy reached $80 \%$ for the Au-siRNA-PAA-AS1411 group with a concentration of $10 \mathrm{nM} \mathrm{Au-siRNA-PAA-AS1411}$ and up to $48 \mathrm{~h}$ of incubation $\left(\mathrm{n}=3\right.$, $\left.{ }^{* * *} P<0.005\right)$; $\mathbf{c}$, d TEM images of $\mathrm{NCl}$-H889 cells incubated with $500 \mathrm{\mu g} \mathrm{mL}^{-1}$ Au-siRNA-PAA-AS1411 nanocages 

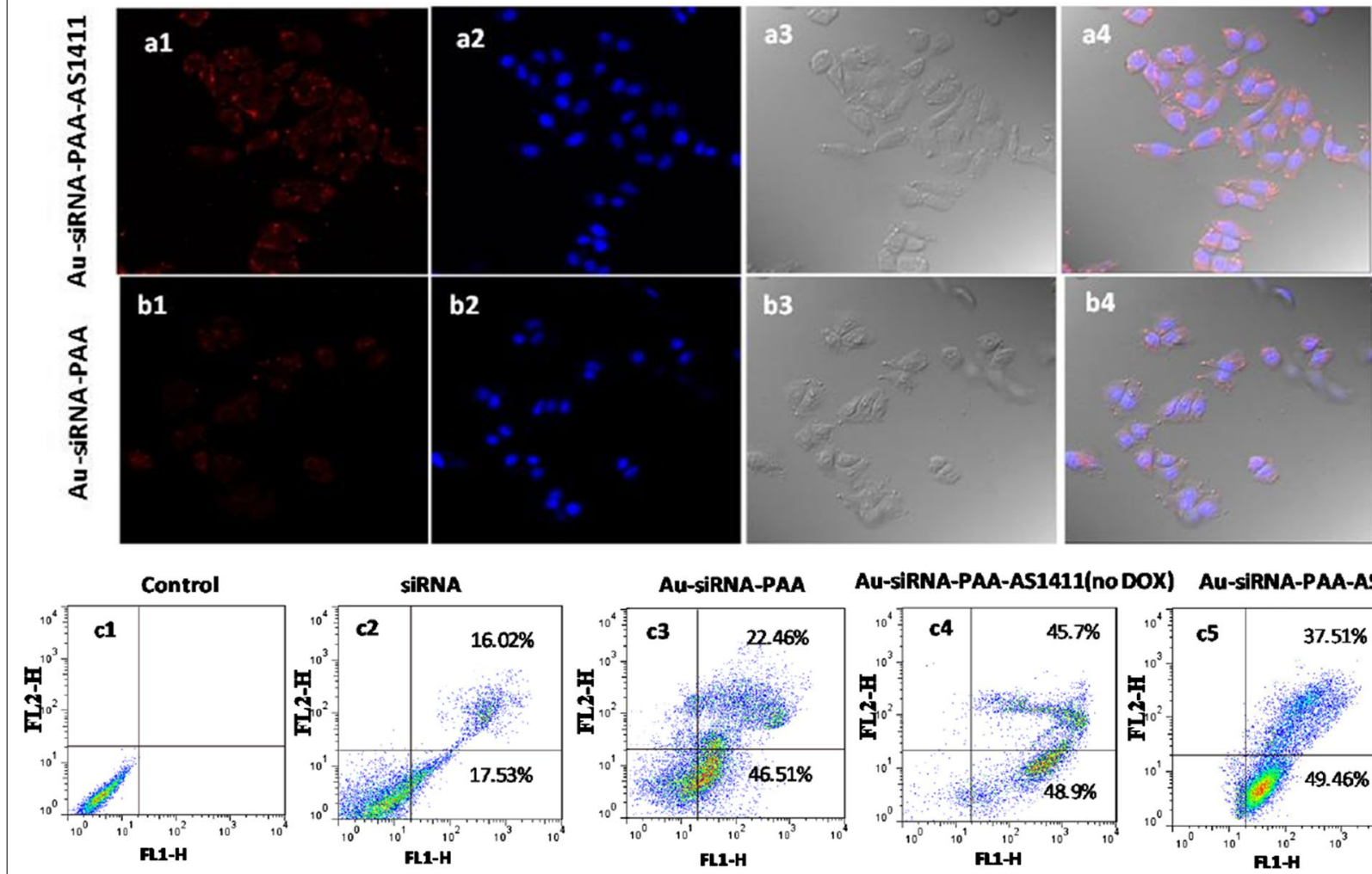

Au-siRNA-PAA-AS1411(no DOX) Au-siRNA-PAA-AS1411

Fig. 4 Confocal images and cell apoptosis levels of NCl-H889 cells incubated with the Au-siRNA-PAA-AS1411 /Au-siRNA-PAA nanocages. a $\mathrm{NCl}-\mathrm{H} 889$ cells incubated with $100 \mathrm{\mu g} \mathrm{mL}^{-1}$ Au-siRNA-PAA-AS1411 for $1 \mathrm{~h}$; b NCI-H889 cells incubated with $100 \mu \mathrm{g} \mathrm{mL}{ }^{-1}$ Au-siRNA-PAA for $1 \mathrm{~h}$. Chanel 1: Fluorescence signal of Au nanocages modified with Cy5; Chanel 2: Hoechst 33,342 signal; Chanel 3: Bright field; Chanel 4: Overlapped field. Magnification: $\times 40$; c Flow cytometric analysis of NCl-H889 cell apoptosis induced by siRNA, Au-siRNA-PAA and Au-siRNA-PAA-AS1411 with the MMP-2 enzyme at $37^{\circ} \mathrm{C}$ for $24 \mathrm{~h}$

lung (tumor) organ exhibited a high degree of overlay with the lung tumor signal (Fig. 5f). Similarly, inductively coupled plasma mass spectrometry (ICP-MS) revealed that after 7 days of treatment with the Au-siRNA-PAAAS1411 nanocages, both Au-siRNA-PAA and Au-siRNAPAA-AS1411 almost exclusively accumulated in the lung tissue (Fig. 5c). As much as an $\sim 12$-fold increase was observed for the Au-siRNA-PAA-AS1411-treated group compared with other organs. The Au-siRNA-PAA group also exhibited an accumulation of the nanoparticle signal, but it was much lower compared with the Au-siRNAPAA-AS1411 group, with an approximate 6-fold increase compared with other organs. Only minimal accumulation was observed in other organs. These findings indicate that Au-siRNA-PAA-AS1411 targeted and accumulate in the tumor-bearing lung after the inhalation-mediated local delivery, and minimal Au-siRNA-PAA-AS1411 nanocages diffused to other organs from the lung.

\section{Drug and gene loading gold nanocages inhibited lung} cancer growth and prolonged the survival of mice

Having established that the Au-siRNA-PAA-AS1411 nanocage could selectively deliver siRNA and DOX to the tumor sites, we next evaluated the lung tumor inhibition ratio using NCI-H889 lung tumor-bearing mice treated with Au-siRNA-PAA-AS1411(no DOX), Au-siRNA-PAA and Au-siRNA-PAA-AS1411 loaded with DOX. To create an orthotopic murine model of lung cancer, NCIH889 lung cancer cells were injected subcutaneously into the lungs of nude mice. Accordingly, BALB/c nude mice bearing NCI-H889 lung tumors were treated with DOXloaded Au-siRNA-PAA-AS1411 gold nanocages at a dose of $1 \mathrm{~mL}\left(800 \mu \mathrm{g} \mathrm{mL}^{-1}\right)$ and administered on days 12,15 , 18, 21, 24, 27, 30, 33 and 36 (Au-siRNA-PAA-AS1411 group). Considering the side effect of the drugs, $808-\mathrm{nm}$ laser irradiation was performed $4 \mathrm{~h}$ after the inhalation administration at a power density of $1 \mathrm{~W} \mathrm{~cm}{ }^{-2}$ for $5 \mathrm{~min}$. 

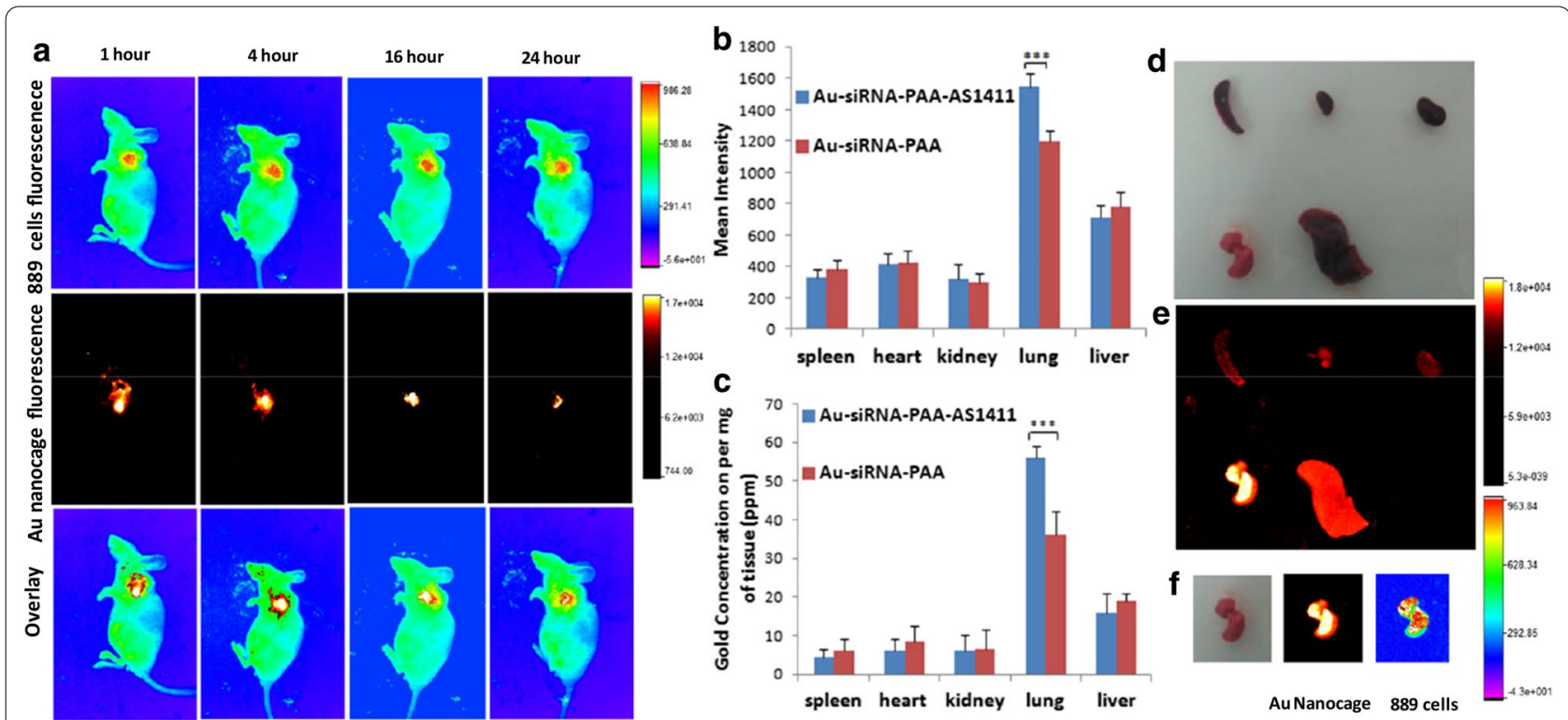

Fig. 5 The ability of gold nanocages to deliver anti-VEGF siRNA to the lung cancer orthotopic murine model of BALB/c nude mice expressing $\mathrm{NCl-H889} \mathrm{lung} \mathrm{cancer} \mathrm{cells.} \mathrm{a} \mathrm{Representative} \mathrm{noninvasive} \mathrm{imagings} \mathrm{of} \mathrm{NCI-H889} \mathrm{tumor-bearing} \mathrm{nude} \mathrm{mice} \mathrm{in} \mathrm{vivo} \mathrm{(inhalation-mediated} \mathrm{local}$ delivery of $1 \mathrm{~mL} 800 \mu \mathrm{g} \mathrm{mL}{ }^{-1}$ Au-siRNA-PAA/Au-siRNA-PAA-AS1411 gold nanocages); (b) Quantitative biodistribution of self-assembled nanoparticles in lung tumors and organs based on the ROI (region of interest) analysis of the mean fluorescence intensity of each organ; c Quantification of Au accumulated in organs by ICP-MS. The data of Au-siRNA-PAA-AS1411 and Au-siRNA-PAA distribution in liver, spleen, lung (tumor), kidney and heart at 7 days after the inhalation-mediated local delivery of gold nanocages. The data in $b$ and $c$ are expressed as the mean $\pm S D\left(n=6,{ }^{* * *} P<0.005\right)$ in each study group; $\mathbf{d}$ The bright field organ imaging of Au-siRNA-PAA-AS1411-treated mice; $\mathbf{e}$ The in vitro organ imaging of Au-siRNA-PAA-AS1411-treated mice; $\mathbf{f}$ Representative NCl-H889 lung-adenocarcinoma cells fluorescence and Au nanocage fluorescence analysis of ex vivo lungs from Au-siRNA-PAA-AS1411-treated mice

Three control groups of mice were treated as follows: (a) the siRNA group, in which mice were administered with siRNA and treated through gene therapy only; (b) the Au-siRNA-PAA group, in which mice were administered with DOX-loaded Au-siRNA-PAA nanocages and passively treated with the combination of siRNA and chemotherapy; and (c) the Au-siRNA-PAA-AS1411(no DOX) group, in which mice were administered with Au-siRNAPAA-AS1411 without DOX loading and targeted treated with the combination of siRNA and thermotherapy. For the thermotherapy therapy groups, the surface temperature of the lungs was increased to $48{ }^{\circ} \mathrm{C}$ after the laser irradiation. The tumor inhibition ratio was calculated using a live animal imaging system to monitor the tdTomato-labeled NCI-H889 lung tumor fluorescence (Fig. 6). Compared to the siRNA groups, tumor-bearing mice subjected to targeted treatment with the combination of gene therapy, chemotherapy and photothermal therapy exhibited the best tumor inhibition ratio, with nearly complete tumor regression after 36 days of treatment. More than a three-fold decrease in tdTomato signal was observed after 18 days of treatment compared with the siRNA group. In comparison, the Au-siRNA-PAA and Au-siRNA-PAA-AS1411 (no DOX) groups also exhibited a good tumor inhibition ratio after 18 days of treatment.
The total fluorescence intensity of the Au-siRNA-PAA and Au-siRNA-PAA-AS1411 (no DOX) groups were stronger than that of the Au-siRNA-PAA-AS1411 group after 36 days of treatment, which exhibited relative weaker tumor inhibition efficiency. The Au-siRNA-PAAAS1411, Au-siRNA-PAA-AS1411 (no DOX) and siRNAsiRNA-PAA groups exhibited a stronger tumor inhibition effect when compared with the siRNA group, as no mice survived after 28 days of treatment with passive targeted gene therapy only. Accordingly, the BALB/c nude mice bearing NCI-H889 lung-adenocarcinoma tumors treated with DOX-loaded Au-siRNA-PAA-AS1411 nanocages exhibited the highest survival rate when the VEGF protein was knocked down in combination with chemotherapy and photothermal therapy (Fig. 6c). In summary, these findings indicate that a combination of gene therapy, chemotherapy and photothermal therapy is far more efficient for tumor inhibition compared with only silencing VEGF using gold nanocages via passive targeting.

The safety of all formulations of gold nanocages was evaluated by monitoring the body weight of the mice. As shown in Fig. 6b, a small decrease in body weight occurred during the first 7 days of administration. However, no significant body weight fluctuation was observed in the following days, suggesting that the gold nanocage doses used 
in the experiments were within the safe range. A steady increase in weight was observed in the Au-siRNA-PAA, Au-siRNA-PAA-AS1411(no DOX) and Au-siRNA-PAAAS1411 groups, much better than that of the siRNA group, which was treated via passive targeted genetic therapy only. The siRNA group exhibited a sharp decline in body weight after 15 days of treatment, and no mice survived after 36 days of treatment.(Fig. 6c) These findings confirm that the combination of gene therapy, chemotherapy and photothermal therapy is far more efficient than genetic therapy only, and the combination therapy prolonged the lives of the mice and improved their health to some extent.

The VEGF silencing effect, antitumor efficacy, and the potential toxicity of the gold nanocages were also evaluated by immunohistochemistry and hematoxylin and eosin (H\&E) staining (Fig. 7). Immunohistochemical staining for VEGF in the lung (tumor) tissue revealed an $\sim 70 \%$ reduction in VEGF for the mice treated with Au-siRNA-PAA-AS1411(DOX), which showed a more significant reduction compared to the mice treated with Au-siRNA-PAA-AS1411(no DOX) and Au-siRNA-PAA (Fig. 7a). A clear difference in lung tumor morphology between the siRNA and Au-siRNA-PAA-AS1411 groups was observed in the H\&E-stained tissues (Fig. 7b). More tumor foci were seen in the siRNA group. These results indicate that the number of tumor cells was decreased in the mice treated with the DOX-loaded Au-siRNA-PAAAS1411 nanoparticles through combined multimodal therapy. To further prove the safety of the gold nanocages, tissue sections from Au-siRNA-PAA-AS1411treated mouse organs were examined to evaluate the potential toxicities. The morphologies of the organs of the treated mice, as shown in Fig. 7c, were similar to those of organs from the untreated healthy mice. Myocardial revealed no myocardial inflammation or necrosis. The liver cells were arranged in order, and no liver cell degeneration, necrosis, or hepatic periportal inflammatory cell infiltration was observed. The glomerulus and tiny tubules of the kidney were normal, with no hyaline change or any necrotic area. Overall, these findings confirmed the good tumor inhibition effect of the combined treatment by Au-siRNA-PAA-AS1411 nanoparticles, and no significant toxicity was evident in mice treated with DOX-loaded Au-siRNA-PAA-AS1411 nanocages.
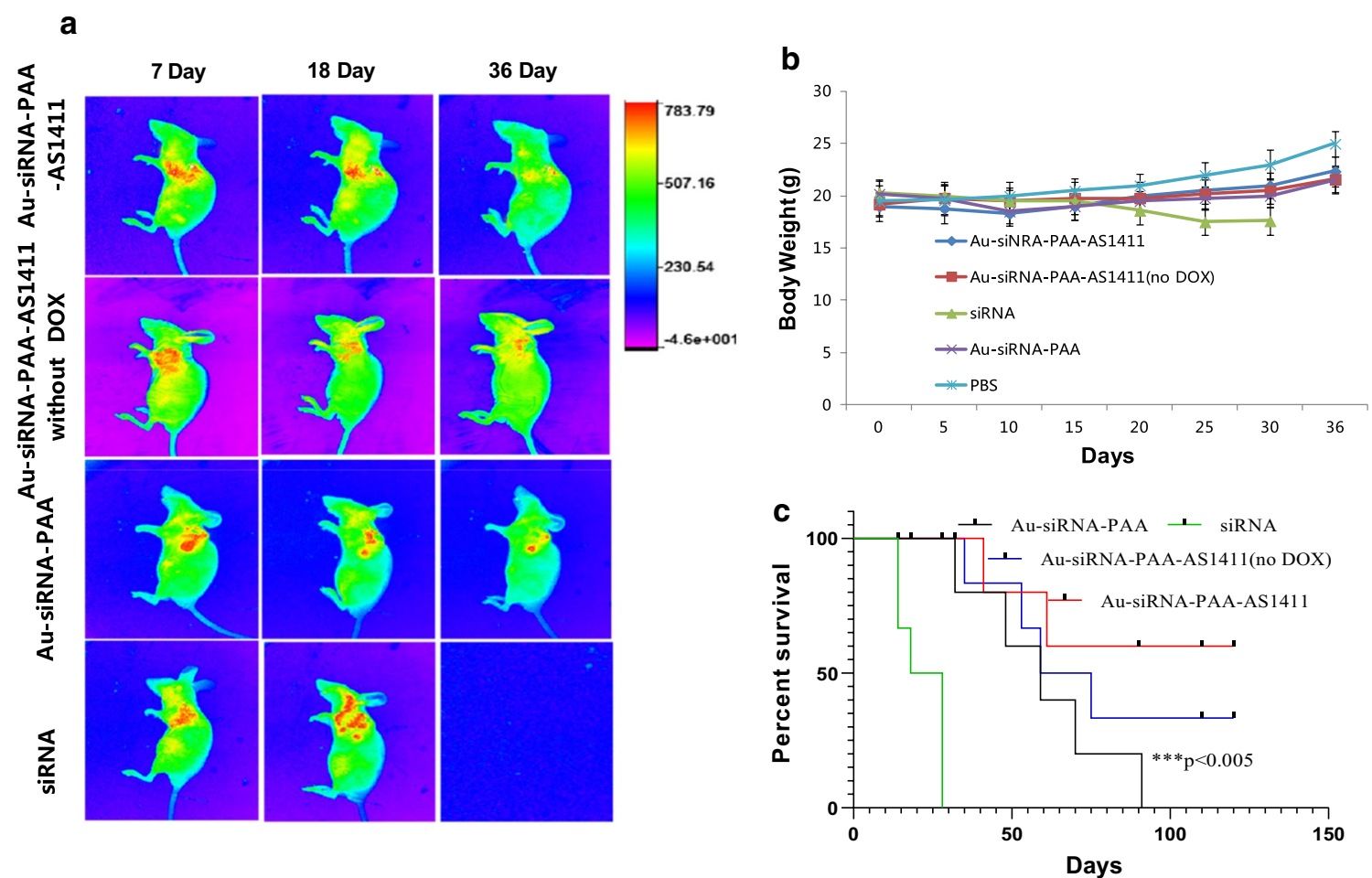

Fig. 6 Lung cancer inhibition ratio and the survival rate of the mice. a Representative non-invasive imagings of lung-adenocarcinoma NCI-H889 tumor-bearing nude mice treated with siRNA, Au-siRNA-PAA, Au-siRNA-PAA-AS1411 (no DOX) and Au-siRNA-PAA-AS1411 nanocages at days 7, 18 and 36; $\mathbf{b}$ Body weight change curve of tumor-bearing mice over the 36 days of treatment. $\mathbf{c}$ Kaplan-Meier survival curves of mice treated with siRNA (green), DOX-loaded Au-siRNA-PAA (black), DOX-loaded Au-siRNA-PAA-AS1411 (red) and Au-siRNA-PAA-AS1411 without DOX(blue). Data represent the mean \pm standard deviation $\left(n=6,{ }^{* * *} \mathrm{P}<0.005\right)$ 


\section{Conclusions}

Gene therapy is an efficient and promising approach to treat malignant tumors by either degrading mRNAs or inhibiting their translation. To address the problems of the degradation of siRNA in serum, the rapid elimination by renal excretion, and the delivery of sufficient amounts of siRNA to target the tumor site, we developed a new gold nanocage vehicle for the delivery of large amounts of siRNA. To maximize the treatment effect, DOX was loaded into the nanocage and released in a controlled manner at the tumor sites together with the siRNAs. Genetic, chemotherapeutic and photothermal combined targeted treatment was realized with the surface modification with the AS1411 aptamer. To avoid degradation and nonspecific uptake and to maximize the therapeutic effect on lung tumors, the aerosol inhalation method was applied for the in vivo experiments. Our results exhibited that targeted silencing combined with chemo and photothermal therapy can inhibit tumor progression and promote increased survival in mice.

This study is the first attempt to construct a nanocage for siRNA delivery and achieve the controlled release of siRNA and drugs by taking advantage of MMP-2 cleavable peptide. Any kind of siRNA used for lung tumor inhibition could be loaded, and the siRNA sequence could also be replaced with other sequences of siRNA that are more efficient for lung cancer or treating other diseases. In addition, gold nanoparticles exhibited to be an excellent X-ray contrast agent due to their high X-ray attenuation and nontoxicity, which facilitated a more accurate visualization of the controlled target drug release. We expect that this new kind of drug and gene vehicle will be the basis for more efficient therapeutics for treating lung cancer. A similar strategy could be applied to treat other diseases associated with the overexpression of specific markers.

\section{Materials and methods Materials and reagents}

The Anti-VEGF antibody was purchased from abcam. DNAs and siRNAs were purchased from Sangon Biotech (Shanghai) and Jinweizhi Company. DOX were purchased from Aladdin Company (Shanghai, China).

\section{Synthesis and characterization of gold nanoparticles}

The 10-nm gold nanoparticles were synthesized by first dissolving $\mathrm{HAuCl}_{4}(1 \mathrm{~mL}, 1 \% \mathrm{w} / \mathrm{v})$ in Nanopure ${ }^{\mathrm{TM}}$ $\mathrm{H}_{2} \mathrm{O}$ water $(100 \mathrm{~mL})$ with magnetic stirring, heating until reflux, then subsequently adding $1 \mathrm{~mL}$ trisodium citrate $(3 \% \mathrm{w} / \mathrm{v})$. Heating was continued for $7 \mathrm{~min}$, at which time the reaction bottle was immediately placed on ice without stirring. The resulting solution of gold nanoparticles was used without further purification for later experiments. Based on the TEM analysis, the average particle size was approximately $10 \mathrm{~nm}$. The concentration of the AuNPs was analyzed by UV-vis absorbance spectroscopy and calculated according to the following formula: $\mathrm{A}=\varepsilon \mathrm{lc}$ ( $\mathrm{A}$ is the absorbance, $\varepsilon$ is the molar absorption coefficient, $l$ is the thickness of the liquid layer, and $\mathrm{c}$ is the liquid concentration). The $\varepsilon$ is $1.37 * 108 \mathrm{M}^{-1} \mathrm{~cm}^{-1}$ for $\lambda=523 \mathrm{~nm}$ of $10 \mathrm{~nm} \mathrm{Au}$ nanoparticle [39].

\section{Surface functionalization of AuNPs}

The gold nanoparticles used for oligonucleotide conjugation were first treated with bis(p-sulfonatophenyl) phenylphosphine dihydrate dipotassium salt (BSPP), and then $300 \mathrm{nM}$ gold nanoparticles was incubated with 800-fold of thiolated DNA-2 and siRNA (DNA2:siRNA $=1: 10$ molar ratio) in 0.5x TBE for more than 12 hrs. Next, $5 \mathrm{M} \mathrm{NaCl}$ was added in six increments to bring the final concentration to $300 \mathrm{mM}$, and aliquots were taken every 2 to $3 \mathrm{hrs}$. Centrifugation $(8,000 \mathrm{rpm}$ for $40 \mathrm{~min}$ ) was applied to get rid of the salt and free DNA. Finally, the UV-Vis of the final AuNPs was measured to calculate the molar concentration.

\section{Gold nanocage construction}

PAA functionalization with oligonucleotides was performed by carbodiimide chemistry assisted by N-hydroxysuccinimide (EDC/NHS coupling reaction) between the carboxylated PAA and the primary amine groups of the oligonucleotides. PAA-1 was conjugated with 5-fold molar ratios of DNA-1, DNA-3 and the AS1411 aptamer. The resultant products were purified by dialysis for 72 hrs. PAA-2 was conjugated with 5-fold molar ratios of DNA-1, DNA-4 and the AS1411 aptamer. 20 nM DNA-2 oligonucleotide functionalized gold nanoparticles were incubated with $100 \mathrm{nM}$ PAA-1, PAA-2 and $150 \mathrm{nM}$ ssDNA -5 in $0.5 x$ TBE overnight. The final gold nanocages were purified by centrifugation at $10,000 \times g$ for $30 \mathrm{~min}$ in $0.5 \times$ TBE 2 to 3 times. To determine the average size, particle distribution and morphology of the gold nanocages, samples were analyzed through DLS and field emission TEM (JEM-2100F). $1 \mathrm{mg} \mathrm{mL}^{-1}$ uranyl acetate was selected for negative staining. The gold nanocage solution was dripped onto a carbon film-supported copper mesh and allowed to air dry before being subjected to TEM observation.

\section{DOX loading in the Au-siRNA-PAA-AS1411 nanocage}

To investigate the amount of DOX loading in the DNA nanostructure, $5 \mu \mathrm{M}$ Au-siRNA-PAA-AS1411 nanocage was incubated with DOX $(1 \mathrm{mM})$ in $10 \mathrm{mM}$ PBS ( $\mathrm{pH}$ 7.4) for $24 \mathrm{hr}$. Then centrifuge, test the concentration of DOX in the supernatant. The molar ratio of 


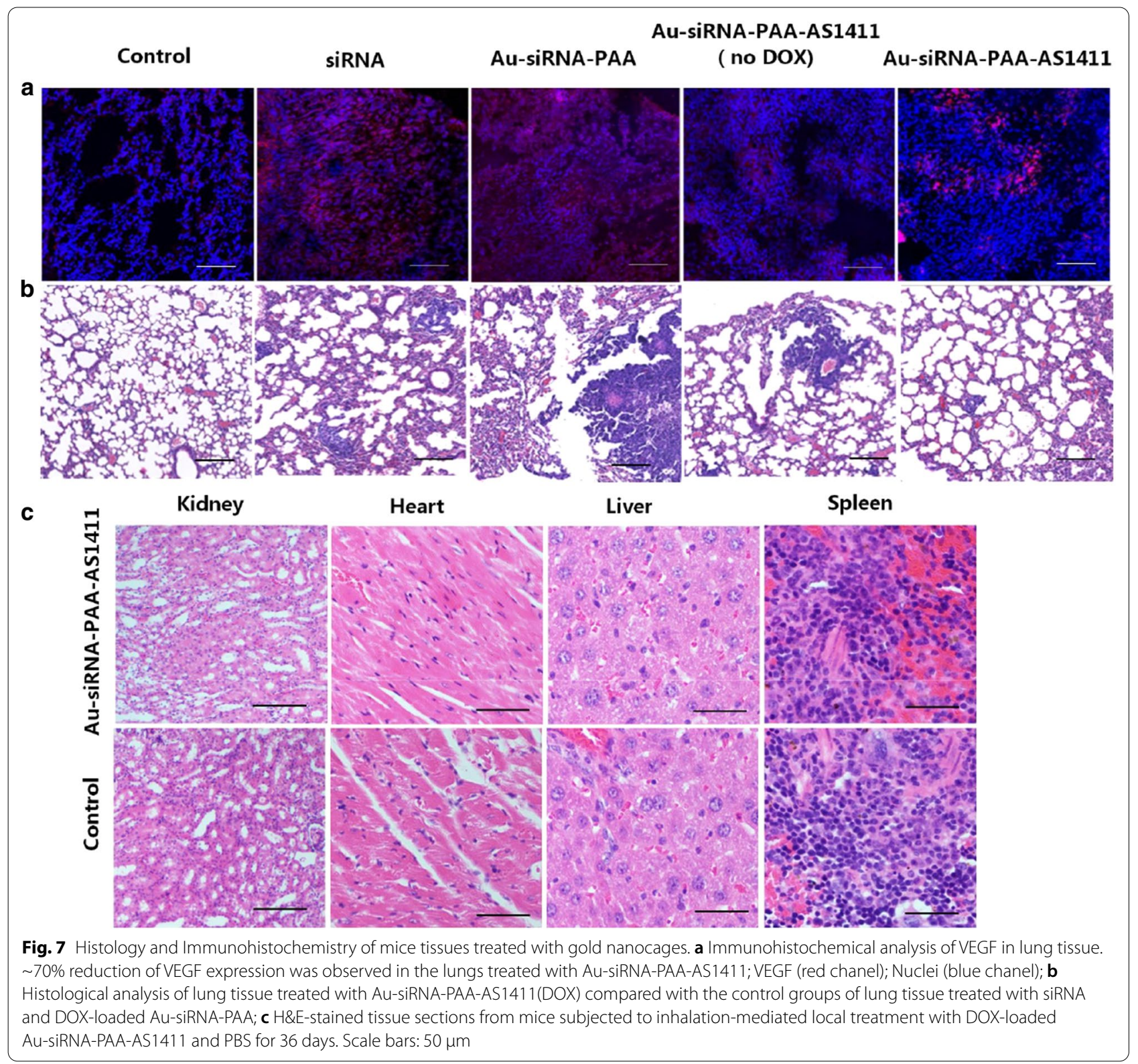

Au-siRNA-PAA-AS1411: DOX was 1:50.5 and this ratio was utilized in the subsequent experiments.

\section{In vitro siRNA/drug release from the gold nanocages}

A dialysis method was employed to investigate the release behavior of siRNA and DOX from the gold nanocages. First, $3 \mathrm{~mL}$ of gold nanocage was transferred into a dialysis bag with 18,000 MWCO. The dialysis bag was then dipped into a $50-\mathrm{mL}$ cell culture medium containing $10 \%$ serum and incubated at $37{ }^{\circ} \mathrm{C}$ with continuous stirring at $200 \mathrm{rpm}$ for as long as $72 \mathrm{~h}$. The, $0.3 \mathrm{~mL}$ of the external cell culture medium was removed for analysis at predetermined time intervals, and an equal volume of dialysis solution was replenished. The amount of Cy5 modified siRNA released was quantified by measuring the fluorescence signal of Cy5. The DOX concentration was measured by HPLC.

\section{Cell culture}

The lung-adenocarcinoma NCI-H889 cell line was selected for the in vitro targeting and cell apoptosis experiments. The lung-adenocarcinoma NCI-H889 cell line was cultured in DMEM with $10 \%$ heat inactivated fetal bovine serum (Gibco), 100 units of potassium penicillin and $100 \mu \mathrm{g}$ of streptomycin sulfate per $1 \mathrm{~mL}$ of culture media at $37^{\circ} \mathrm{C}$ in $5 \% \mathrm{CO}_{2}$. 


\section{Cellular uptake and distribution of self-assembled nanodrugs}

The lung-adenocarcinoma NCI-H889 cells were seeded onto 28-mm glass cover slips for $24 \mathrm{~h}$ before being incubated with the gold nanocages. Then, the cells were incubated with $100 \mu \mathrm{g} \mathrm{mL} \mathrm{m}^{-1} \mathrm{Au}$-siRNA-PAA-AS1411 / $\mathrm{Au}$-siRNA-PAA nanocages at $37{ }^{\circ} \mathrm{C}$ for $1 \mathrm{~h}$, then washed twice with PBS and fixed with a $4 \%$ paraformaldehyde solution for $30 \mathrm{~min}$ at room temperature. The nuclei were then stained with Hoechst 33,342 $\left(10 \mu \mathrm{g} \mathrm{mL}^{-1}\right)$ at $37{ }^{\circ} \mathrm{C}$ for $15 \mathrm{~min}$, and the slides were rinsed three times with PBS. A confocal laser scanning microscope (CLSM) (Leica TCS SP8, Germany) was used to detect the cellular uptake and distribution of gold nanocages in the NCIH889 cells. To visualize the cellular distribution of gold nanocages via TEM, NCI-H889 lung-adenocarcinoma cells were incubated with $500 \mu \mathrm{g}$ mL-1 Au-siRNA-PAAAS1411 nanocages for up to $48 \mathrm{~h}$ and then fixed with glutaraldehyde (2.5\%) for more than $1 \mathrm{~h}$. Then, the samples were sent to Shanghai Normal University for TEM testing.

\section{In vivo targeted delivery of gold nanocages}

Lung-adenocarcinoma NCI-H889 cells were selected to construct the lung cancer orthotopic murine model. The lung cancer orthotopic murine model was established by subcutaneously injecting NCI-H889 cells into the lungs of six-week-old BALB/c nude mice after making a $0.5 \mathrm{~cm}$ cut under the front leg of mice. Six BALB/c nude mice bearing NCI-H889 lung tumors in each group were injected with $1 \mathrm{~mL} 800 \mu \mathrm{g} \mathrm{mL}^{-1} \mathrm{Au}$-siRNA-PAAAS1411 and Au-siRNA-PAA gold nanoparticles through the inhalation-mediated local delivery method. The fluorescence distribution was monitored at $1 \mathrm{~h}, 4 \mathrm{~h}, 16 \mathrm{~h}$ and $24 \mathrm{~h}$ using a small animal in vivo imaging system with the appropriate wavelengths. The mice used for the in vitro organ imaging were killed $4 \mathrm{~h}$ after the gold nanocages were administered. All animal experiment was authorized according to the Shanghai Jiao Tong University Animal Care guidelines.

\section{Tumor inhibition activity of gold nanocages}

BALB/c nude mice bearing the NCI-H889 orthotopic murine model of lung cancer were treated with $\mathrm{Au}$ siRNA-PAA-AS1411 gold nanocages on days $12,15,18$, $21,24,27,30,33$, and 36 . Considering the wastage in the course of inhalation administration, $1 \mathrm{~mL} 800 \mu \mathrm{g} \mathrm{mL}^{-1}$ Au-siRNA-PAA-AS1411 gold nanocages were used. Then, 808-nm laser irradiation was performed after 4 $\mathrm{h}$ of the inhalation administration at a power density of $1 \mathrm{~W} \mathrm{~cm}{ }^{-2}$ for $5 \mathrm{~min}$. Three groups of orthotopic lung tumor-bearing mice treated with siRNA, DOX-loaded
Au-siRNA-PAA and Au-siRNA-PAA-AS1411 (no DOX) were used as the control. All experiments included six mice per treatment group unless otherwise noted.

\section{Quantitative PCR}

Total RNA from lung-adenocarcinoma NCI-H889 cells and from tissues from tumor-bearing mice was extracted using the RNeasy Plus Mini Kit according to the manufacture's protocol. qRT-PCR was performed with the SuperScript $^{\mathrm{TM}}$ III One-Step RT-PCR System with the Platinum $^{\mathrm{TM}}$ Taq DNA Polymerase Kit. The samples were placed in the preheated thermal cycler, which was programmed with the following thermal cycling procedure: $45 \sim 60{ }^{\circ} \mathrm{C}$ for $30 \mathrm{~min} ; 2 \mathrm{~min}$ at $94{ }^{\circ} \mathrm{C} ; 40$ cycles $15 \mathrm{~s}$ at $94{ }^{\circ} \mathrm{C}, 30 \mathrm{~s}$ at $55 \sim 66{ }^{\circ} \mathrm{C}, 1 \mathrm{~min}$ at $68{ }^{\circ} \mathrm{C}$; finally, 1 cycle $5 \mathrm{~min}$ at $68^{\circ} \mathrm{C}$. GAPDH was used as the reference gene.

\section{Histology and immunohistochemistry}

Freshly removed lung tumor tissues and other organs were rinsed with sterile PBS, frozen with liquid nitrogen and sectioned with a cryostat microtome. For the immunohistochemical analysis, lung (tumor) sections were first fixed with $4 \%$ paraformaldehyde for $15 \mathrm{~min}$, then treated with $0.25 \%$ TritonX-100 for $10 \mathrm{~min}$ and washed with PBS three times. Next, the tissues were blocked in PBST containing 1\% BSA for $30 \mathrm{~min}$ and then washed with PBS 3 times. Then, the tissue was incubated with an anti-VEGF antibody for $1 \mathrm{~h}$ at room temperature and then washed three times with PBS. Then, the tissues were incubated with the secondary antibody (Alexa Fluor 532 goat anti-mouse IgG, 1:250, Invitrogen) for $1 \mathrm{~h}$ at room temperature and subsequently washed 3 times with PBS. The nuclei were then stained with Hoechst $33,342\left(10 \mu \mathrm{g} \mathrm{mL}^{-1}\right)$ at $37^{\circ} \mathrm{C}$ for $15 \mathrm{~min}$ and then rinsed three times with PBS. For H\&E staining, the organs were cut into small pieces and fixed with $4 \%$ paraformaldehyde, embedded in paraffin, sectioned and stained according to the standard procedures. All tissues were harvest alter 36 days treatment except the siRNA group, which were harvest after 28 days treatment. All slices were examined by CLSM (Leica TCS SP8, Germany).

\section{Statistical analysis}

Data are presented as the mean $\pm S D$ unless otherwise indicated. Differences between groups were examined using Student's t-test. Statistically significant $\mathrm{P}$ values were indicated in figures or captions as *** $\mathrm{P}<0.005 ; \quad * * \mathrm{P}<0.01 ; * \mathrm{P}<0.05$. All in vivo experiments used six mice per treatment group unless noted otherwise. 


\section{Supplementary Information}

The online version contains supplementary material available at https://doi. org/10.1186/s12951-020-00759-3.

Additional file 1: Figure S1. Quantification the amounts of DNA strands loading on gold nanoparticles. (a) $10 \mathrm{~nm}$ gold nanoparticles were coated with 130 strands of DNA per nanoparticle, corresponding to a 1:130 molar ratios; (b) The amount of antisense DNAs binding on the gold nanoparticles with 500:1 incubation molar ratio. Figure S2. DLS curve of Au-siRNA PAAAS1411. Figure S3. Profile of Dox release from the Au-siRNAPAA-AS1411 nanocage in PBS buffer at $37^{\circ} \mathrm{C}$ in pH 7.4 (bottom) and in pH 5.5 (top). Figure S4. Profile of siRNA release from the Au-siRNA-PAAAS1411 nanocage in PBS buffer at $37^{\circ} \mathrm{C}$ in pH 7.4 and in pH 5.5. Table S1. The sequence of DNAs.

\section{Abbreviations}

DOX: Doxorubicin hydrochloride; VEGF : The vascular endothelial growth factor; NPs: Nanoparticles; siRNA : Small interfering RNA; M-MSN : Magnetic mesoporous silica nanoparticle; siVEGF: VEGF-targeted siRNA; PEI : Polyethylenimine; PAA: Polyacrylic acid; ssDNA: Single strand DNA; MMP: Matrix metalloproteinase enzymes.

\section{Acknowledgements}

We are grateful to the Instrumental Analysis Center of Shanghai Jiao Tong University for providing experimental equipment.

\section{Authors' contributions}

YY: Article writing, participate in all experiments in the article. YH: Participate in many experiments in the article. JC and QS: Responsible for electron microscopic characterization of nanoparticles. CY and YL: Establishment of orthotopic lung cancer model in mice, histology and immunohistochemistry analysis of mice tissues. JS: Guiding the experiment of coating sulfydryl siRNAs on gold nanoparticles. WJ: Supply tdTomato-labeled NCI-H889 cells. XD: Quantification of Au accumulated in organs by ICP-MS. JMdelaF: Supply the effective sequence of anti-VEGF siRNA. JN: Responsible for TEM images of NCI-H889 cells incubated with Au-siRNA-PAA-AS1411 nanocages. XW: The conception of nanocage structure, revision of articles. DC: The conception of nanocage structure, revision of articles and financial Support. All authors read and approved the final manuscript.

\section{Funding}

This work is supported by the Special fund for science and technology innovation of Shanghai Jiao Tong University (YG2017MS70, YG2015MS62, AF0300179 ), National Key Basic Research Program (973 Project) (No.2015CB931802), National Key Research and Development Program of China (2017FYA0205301), Shanghai Municipal Bureau of Economy and Information Technology (XC-ZXSJ-02-2016-05), the National Natural Scientific Foundation of China (Grant Nos. 81225010, 81028009 and 31170961), the 863 project of China (Project No. 2014AA020700) and the Shanghai Science and Technology Fund (13NM1401500)

\section{Availability of data and materials}

All data generated or analyzed during this study are included in this article.

\section{Ethics approval and consent to participate}

The animal experiment was authorized according to the Shanghai Jiao Tong University Animal Care guidelines.

\section{Consent for publication}

Not applicable.

\section{Competing interests}

The authors declared that they have no conflicts of interest to this work.

\section{Author details}

${ }^{1}$ Institute of Nano Biomedicine and Engineering, Key Laboratory for Thin Film and Microfabrication Technology of the Ministry of Education, Shanghai Engineering Research Center for Intelligent Diagnosis and Treatment Instrument,
Department of Instrument Science \& Engineering, School of Electronic Information and Electrical Engineering, Shanghai Jiao Tong University, 800 Dongchuan Road, Shanghai 200240, People's Republic of China. ${ }^{2}$ National Center for Translational Medicine, Collaborative Innovational Center for System Biology, Shanghai Jiao Tong University, 800 Dongchuan RD, Shanghai 200240, People's Republic of China. ${ }^{3}$ Pediatric Neurological Disease Center, Xinhua Hospital, Shanghai Jiaotong University School of Medicine, Number 1665, Kongjiang Road, Shanghai 200092, People's Republic of China. ${ }^{4}$ School of Biomedical Engineering, Shanghai Jiao Tong University, 200240 Shanghai, People's Republic of China. ${ }^{5}$ Instituto de Nanociencia de Aragon (INA), Universidad de Zaragoza, Zaragoza 50018, Spain.

Received: 12 Auqust 2020 Accepted: 15 December 2020

Published online: 24 February 2021

\section{References}

1. Garbuzenko OB, Saad M, Pozharov VP, Reuhl KR, Mainelis G, Minko T: Inhibition of lung tumor growth by complex pulmonary delivery of drugs with oligonucleotides as suppressors of cellular resistance. Proc Natl Acad Sci. 2010;107:10737-10742.

2. Yang ZR, Wang HF, Zhao J, Peng YY, Wang J, Guinn BA, Huang LQ. Recent developments in the use of adenoviruses and immunotoxins in cancer gene therapy. Cancer Gene Ther. 2007;14:599.

3. Wang JL, Tang GP, Shen J, Hu QL, Xu FJ, Wang QQ, Li ZH, Yang WT. A gene nanocomplex conjugated with monoclonal antibodies for targeted therapy of hepatocellular carcinoma. Biomaterials. 2012:33:4597-607.

4. Jain S, Pathak K, Vaidya A. Molecular therapy using siRNA: Recent trends and advances of multi target inhibition of cancer growth. Int J Biol Macromol. 2018;116:880-92.

5. Chen Y, Wang X, Liu T, Zhang DS, Wang Y, Gu H, Di W. Highly effective antiangiogenesis via magnetic mesoporous silica-based siRNA vehicle targeting the VEGF gene for orthotopic ovarian cancer therapy. Int J Nanomed. 2015;10:2579-94.

6. Toledo RA, Garralda E, Mitsi M, Pons T, Monsech J, Vega E, Otero A, Albarran MI, Banos N, Duran Y, et al. Exome sequencing of plasma DNA Portrays the mutation landscape of colorectal cancer and discovers mutated VEGFR2 receptors as modulators of antiangiogenic therapies. Clin Cancer Res. 2018;24:3550-9.

7. Ferrara N. Vascular endothelial growth factor: Basic science and clinical progress. Endocr Rev. 2004;25:581-611.

8. Petit AMV, Rak J, Hung MC, Rockwell P, Goldstein N, Fendly B, Kerbel RS. Neutralizing antibodies against epidermal growth factor and ErbB-2/ neu receptor tyrosine kinases down-regulate vascular endothelial growth factor production by tumor cells in vitro and in vivo - Angiogenic implications for signal transduction therapy of solid tumors. Am J Pathol. 1997;151:1523-30.

9. He YL, Rajantie I, Pajusola K, Jeltsch M, Holopainen T, Yla-Herttuala S, Harding T, Jooss K, Takahashi T, Alitalo K. Vascular endothelial cell growth factor receptor 3-mediated activation of lymphatic endothelium is crucial for tumor cell entry and spread via lymphatic vessels. Can Res. 2005;65:4739-46.

10. Song EW, Zhu PC, Lee SK, Chowdhury D, Kussman S, Dykxhoorn DM, Feng Y, Palliser D, Weiner DB, Shankar P, et al. Antibody mediated in vivo delivery of small interfering RNAs via cell-surface receptors. Nat Biotechnol. 2005;23:709-17.

11. Takei Y, Kadomatsu K, Yuzawa Y, Matsuo S, Muramatsu T. A small interfering RNA targeting vascular endothelial growth factor as cancer therapeutics. Can Res. 2004;64:3365-70.

12. Niethammer AG, Xiang R, Becker JC, Wodrich H, Pertl U, Karsten $G$, Eliceiri BP, Reisfeld RA. A DNA vaccine against VEGF receptor 2 prevents effective angiogenesis and inhibits tumor growth. Nat Med. 2002;8:1369-75.

13. Reddy AB, Manjula B, Jayaramudu T, Sadiku ER, Anand Babu P, Periyar Selvam S. Fluorouracil Loaded Chitosan-PVA/Na + MMT nanocomposite films for drug release and antimicrobial activity. Nano-Micro Lett. 2016;8:5 
14. Mathiyazhakan M, Wiraja C, Xu C. A concise review of gold nanoparticles-based photo-responsive liposomes for controlled drug delivery. Nano-Micro Lett. 2017;10:10.

15. Allen TM, Cullis PR. Liposomal drug delivery systems: from concept to clinical applications. Adv Drug Deliv Rev. 2013;65:36-48.

16. Kratz F. Albumin as a drug carrier: Design of prodrugs, drug conjugates and nanoparticles. J Controlled Release. 2008;132:171-83.

17. Park JH, Gu L, von Maltzahn G, Ruoslahti E, Bhatia SN, Sailor MJ. Biodegradable luminescent porous silicon nanoparticles for in vivo applications. Nat Mater. 2009;8:331-6.

18. Yohan D, Cruje C, Lu X, Chithrani DB. Size-dependent gold nanoparticle interaction at nano-micro interface using both monolayer and multilayer (Tissue-Like) cell models. Nano-Micro Letters. 2016;8:44-53.

19. Danhier F, Feron O, Preat $V$. To exploit the tumor microenvironment: Passive and active tumor targeting of nanocarriers for anti-cancer drug delivery. J Controlled Release. 2010;148:135-46.

20. Ito A, Shinkai M, Honda H, Kobayashi T. Medical application of functionalized magnetic nanoparticles. J Biosci Bioeng. 2005;100:1-11.

21. Yang Y, Yue C, Han Y, Zhang W, He A, Zhang C, Yin T, Zhang Q, Zhang J, Yang $Y$, et al. Tumor-responsive small molecule self-assembled nanosystem for simultaneous fluorescence imaging and chemotherapy of lung cancer. Adv Func Mater. 2016;26:8735-45.

22. Wang AZ, Langer R, Farokhzad OC. Nanoparticle Delivery of Cancer Drugs. In Annual Review of Medicine, Vol 63. Caskey CT, Austin CP, Hoxie JA, eds. Palo Alto: Annual Reviews; 2012. p. 185-198.

23. Idris NM, Gnanasammandhan MK, Zhang J, Ho PC, Mahendran $R$, Zhang $Y$. In vivo photodynamic therapy using upconversion nanoparticles as remote-controlled nanotransducers. Nat Med. 2012;18:1580-U1190.

24. Jain TK, Morales MA, Sahoo SK, Leslie-Pelecky DL, Labhasetwar V. Iron oxide nanoparticles for sustained delivery of anticancer agents. Mol Pharm. 2005;2:194-205.

25. Kim SH, Jeong JH, Lee SH, Kim SW, Park TG. Local and systemic delivery of VEGF siRNA using polyelectrolyte complex micelles for effective treatment of cancer. J Controlled Release. 2008;129:107-16.

26. Ding X, Su Y, Wang C, Zhang F, Chen K, Wang Y, Li M, Wang W. Synergistic suppression of tumor angiogenesis by the co-delivering of vascular endothelial growth factor targeted siRNA and candesartan mediated by functionalized carbon nanovectors. ACS Appl Mater Interfaces. 2017:9:23353-69.

27. Finlay J, Roberts CM, Dong J, Zink JI, Tamanoi F, Glackin CA. Mesoporous silica nanoparticle delivery of chemically modified siRNA against TWIST1 leads to reduced tumor burden. Nanomed Nanotechnol Biol Med. 2015;11:1657-66.

28. Dhar S, Daniel WL, Giljohann DA, Mirkin CA, Lippard SJ. Polyvalent oligonucleotide gold nanoparticle conjugates as delivery vehicles for Platinum(IV) Warheads. J Am Chem Soc. 2009;131:14652.
29. Zhang GD, Yang Z, Lu W, Zhang R, Huang Q, Tian M, Li L, Liang D, Li C. Influence of anchoring ligands and particle size on the colloidal stability and in vivo biodistribution of polyethylene glycol-coated gold nanoparticles in tumor-xenografted mice. Biomaterials. 2009;30:1928-36.

30. Dixit V, Van den Bossche J, Sherman DM, Thompson DH, Andres RP. Synthesis and grafting of thioctic acid-PEG-folate conjugates onto Au nanoparticles for selective targeting of folate receptor-positive tumor cells. Bioconjug Chem. 2006;17:603-9.

31. Llevot A, Astruc D. Applications of vectorized gold nanoparticles to the diagnosis and therapy of cancer. Chem Soc Rev. 2012;41:242-57.

32. Bae Y, Kataoka K. Intelligent polymeric micelles from functional poly(ethylene glycol)-poly(amino acid) block copolymers. Adv Drug Deliv Rev. 2009;61:768-84.

33. Yuan L, Tang QQ, Yang D, Zhang JZ, Zhang FY, Hu JH. Preparation of $\mathrm{pH}$-responsive mesoporous silica nanoparticles and their application in controlled drug delivery. J Phys Chem C. 2011;115:9926-32.

34. Zhu W, Li YL, Liu LX, Zhang WL, Chen YM, Xi F. Biamphiphilic triblock copolymer micelles as a multifunctional platform for anticancer drug delivery. J Biomed Mater Res A. 2011;96A:330-40.

35. Lu L, Zou Y, Yang WJ, Meng FH, Deng C, Cheng R, Zhong ZY. Anisamide-Decorated $\mathrm{pH}$-sensitive degradable chimaeric polymersomes mediate potent and targeted protein delivery to lung cancer cells. Biomacromol. 2015;16:1726-35.

36. Dong L, Xia S, Wu K, Huang Z, Chen H, Chen J, Zhang J. A pH/Enzymeresponsive tumor-specific delivery system for doxorubicin. Biomaterials. 2010;31:6309-16.

37. Chou LYT, Zagorovsky K, Chan WCW. DNA assembly of nanoparticle superstructures for controlled biological delivery and elimination. Nat Nanotechnol. 2014;9:148.

38. Conde J, Bao C, Tan Y, Cui D, Edelman ER, Azevedo HS, Byrne HJ, Artzi N, Tian F. Dual targeted immunotherapy via in vivo delivery of biohybrid RNAi-peptide nanoparticles to tumor-associated macrophages and cancer cells. Adv Func Mater. 2015;25:4183-94.

39. Haiss W, Thanh NT, Aveyard J, Fernig DG. Determination of size and concentration of gold nanoparticles from UV-vis spectra. Anal Chem. 2007;79:4215-21.

\section{Publisher's Note}

Springer Nature remains neutral with regard to jurisdictional claims in published maps and institutional affiliations.
Ready to submit your research? Choose BMC and benefit from:

- fast, convenient online submission

- thorough peer review by experienced researchers in your field

- rapid publication on acceptance

- support for research data, including large and complex data types

- gold Open Access which fosters wider collaboration and increased citations

- maximum visibility for your research: over $100 \mathrm{M}$ website views per year

At BMC, research is always in progress.

Learn more biomedcentral.com/submissions 